\title{
Constructing hegemonic masculinities in South Africa: The discourse and rhetoric of heteronormativity
}

\author{
Russell Luyt
}

\begin{abstract}
This paper considers how local and regional representations of hegemonic masculinity are (re)produced, and how men's gender identities are constituted through situated interaction in South Africa. It points toward the important role played by the discourse and rhetoric of heteronormativity among these men in hegemonic sense-making, and in particular, the underlying discursive practices of performative/intimate ( hetero)sexuality and homosexual rejection/acceptance. An attempt is made to account for complexity and diversity in this sense-making across intersecting social categories such as ethnicity and social class. Focus group discussion among Afrikaans, English and Xhosa men was transcribed and back-translated where necessary. A technique of discourse analysis that considers the rhetorical aspects of text is developed through the introduction of norm-referencing rhetorical devices. Findings highlight the extent to which practices of both compliance and resistance contribute toward the (re)production of masculinities.
\end{abstract}

keywords: discourse; hegemonic masculinities; heteronormativity; rhetoric; south africa

\section{Introduction}

This paper considers how dominant representations of masculinity are (re)produced, and how men's gender identities are constituted through situated interaction. It highlights the role played by the dominant discourse and rhetoric of heteronormativity in South African (SA) men's gender understanding. This is worthwhile. Firstly, as Connell (1993: 600) argues, English-language literature is ethnocentric in its attempt to make sense of masculinities through the experience of '(at most) 5 percent of the world's population of men, in one culture-area, at one moment in history' Anthropological research has challenged this ethnocentrism somewhat over the last two decades by describing diversity in men's experiences. This study contributes toward accounts of diversity in gender sense-making within a non-Western context. Secondly, SA provides a rich research site in which to explore such diversity due to its social-cultural plurality, as well as its turbulent political history. Lastly, a focus on heteronormativity among SA men has important social implications, given the link between dominant constructions of men's (hetero)sexuality and homophobia (Msibi 2009), 
sexual health (Ragnarsson et al. 2008), and sexual violence against women (Jewkes and Morrell 2010) in SA and elsewhere in Africa. The concept of hegemonic masculinity/ies (Connell 1995; Connell and Messerschmidt 2005) provides a useful theoretical framework for this study. This concept has been subject to much discussion. Hegemonic masculinity, a critique of the concept, and its relevance to SA, are briefly considered below.

The notion of hegemonic masculinity has inspired a great deal of research literature (e.g. Cooper 2009; Light and Kirk 2000). Unsurprisingly it has also therefore stimulated a great deal of theoretical debate (e.g. Hall 2002; Schippers 2007). It was originally defined 'as the configuration of gender practice which embodies the currently accepted answer to the problem of the legitimacy of patriarchy, which guarantees (or is taken to guarantee) the dominant position of men and the subordination of women' (Connell 1995: 77). This definition is firmly grounded in social constructionism. Gender is neither believed to be biologically nor psychologically determined (Jeff erson 2002). Nor is it merely considered to be a set of social expectations or an identity (Connell and Messerschmidt 2005). It comprises configurations of social practice that are informed by, and inform, existing social conditions (Connell 1993). Luyt (2003), for example, argues that hegemonic masculinity in contemporary SA emphasizes the importance of masculine control, (un)emotionality, physicality and toughness, competition, success, responsibility, and (hetero)sexuality.

Hegemonic masculinity never achieves complete consensus or incorporation, is constantly challenged, and changes over time (Connell 1995

For example, the literature testifies to the historical dominance of 'white' men and masculinity in SA. The neo-colonial period, following union ${ }^{1}$ in 1910 and up until the first democratic election in 1994, was marked by the ascendancy and decline in the hegemony of 'white' Afrikaner men and masculinity in particular (Swart 2001; 2004).

Challenge and change to the hegemonic ideal is always present. Louw (2001), for instance, describes the emergence of homosexual practices within the settlement of Mkhumbane during the 1950s. Practices of this kind were argued to have developed from within their own 'rules of formation' (2001: 294) and, as such, displayed distinct continuity with traditional social practices. But their emergence occurred under specific conditions of geographical isolation and political upheaval, in which traditional social practices were disrupted. Their potential for challenge was therefore limited.

As the dominant configuration of gender practice at any historical moment (Hearn 2004), the concept of hegemonic masculinity embodies a culturally idealised form which serves the interests of powerful men by legitimating and maintaining patriarchal gender relations. The ascendancy and maintenance of a particular version of masculinity as hegemonic relies 
on cultural processes. These include texts, images and ideas (Hall 2002). Representations of the ideal are made familiar through institutions such as the mass media (Connell 1995). For example, television advertising in SA continues to reflect traditional hierarchical relations in society, where men are represented as being dominant vis-à-vis women (Luyt 2011), and 'white' men are represented as exemplars of hegemonic masculinity, whilst 'black' men are marginalised (Luyt, in press).

The concept recognises two forms of hierarchy in gender relations: one between men and women, as well as one among men. Hierarchical relations among men are acknowledged through terms such as complicit, subordinated and marginalised masculinities (Connell 1987). Relatively few men are able to practice hegemonic masculinity. Furthermore, it is unlikely to mirror the lived reality of even the most powerful (Connell 1995; 2002). It exists as a cultural ideal and is therefore only partially represented in the social practices of individual men (Connell 2002). Most actively support or passively collaborate in maintaining hegemonic masculinity. They do so, despite both their inability to practice it and the concessions that they may make to women in their everyday lives (Connell 1995). On these occasions they are described as being complicit. Complicity is motivated by either fantasy gratification (Connell 1987) or the benefit they collectively accrue through their shared interest in the subordination of women. The latter is described as the patriarchal dividend (Connell 1995). McClendon (1995) provides a useful example of how 'black' men have been complicit in gender oppression, whilst simultaneously reinforcing their own racial subordination in SA.

Hierarchy between masculinities plays an important role in the functioning of patriarchy, whereby the interests of powerful men are secured (Connell 1987). The notion of subordinated masculinities contributes toward the description of this. Sexuality exists as the most common axis along which hegemonic and subordinate masculinities are distinguished in contemporary Western society, and beyond, as this paper suggests. Heterosexuality is considered a definitive characteristic of masculinity, whereas homosexuality is not. Predictably, eff eminate masculinities are also subordinated, given their association with women (Connell 1995).

Donham (1998) describes how during Apartheid, sexual identity in same-sex male relationships within urban 'black' culture was based on a subtle negotiation of the link between heteronormativity, gender and biological sex. A clear distinction was made between the eff eminate or passive partner versus the active partner in same-sex male relationships. Eff eminate or passive sexual partners were either considered hermaphrodites (i.e. stabane) or members of a second female sex. Alternatively, active sexual partners were thought to remain 'real' men. It is interesting to note that men rarely considered themselves as belonging to a mixed or second female sex. However, in a homophobic context, it was more socially 
acceptable for them to appear as such. Skesanas, as they called themselves, dressed as women and adopted a receptive role during sex. Their participation as 'wives' in men's migrant hostels served to reinforce this identity.

The notion of marginalisation describes how gender intersects with other structures such as class, 'race' and sexuality. Marginalised masculinities are patterns of gender practice that develop among men within oppressed groups. These masculinities may share many features in common with hegemonic masculinity. Dominant men determine when these features are authorised as hegemonic (Connell 1995) but such authorisation does not result in the improved authority of these men in society in general (Jeff erson 2002).

Sexual success appears to be a key way in which marginalised men may practice 'real' masculinity. For example, Campbell (1997; 2001) notes the sexual promiscuity of 'black' men working in gold mines on the Witwatersrand. Poor and unpredictable working conditions, in combination with low levels of self-e fficy, result in a particular construction of masculinity that encourages multiple unprotected sexual encounters as a means through which they may perform assertive masculinity.

The concept of hegemonic masculinity has undoubted worth. Yet it has also generated critique. It is worthwhile reviewing some key criticisms concerning its arguably inadequate theorisation of concepts such as 'self' and 'subjectivity' in particular.

Wetherell and Edley (1999) underline the utility of Connell's framework for social psychological analysis. Nevertheless, together with others (e.g. Je ffrson 2002; Whitehead 1999), they criticise it for its theorisation of the self. Little consideration is aff orded the micro-level processes that operate in men's negotiation of identity in relation to hegemonic masculinity. Moreover, there is limited reflection concerning how these processes may result in identity that is complex and contradictory, or even psychically divided and multilayered (Connell and Messerschmidt 2005). In short 'Connell's account of the discursive/ideological field is... too neat' (Wetherell and Edley 1999: 352). Two questions emerge as being especially important:

What social norms constitute hegemonic masculinity? The concept refers to an ideal form of masculinity, but its content remains ill-defined. Its constituent social norms are not consistent across situations, nor do individuals seem to understand it in precisely the same way. Hegemonic sense-making is clearly diverse, complex and often contradictory. This suggests that there may be more than a single hegemonic form at any time and place. Multiple as well as contradictory discursive resources exist for the construction of gender identity (Wetherell and Edley 1999).

How is hegemonic masculinity (re)produced? Answers should extend beyond the suggestion that men conform to social norms. It is implausible 
to suggest that men may embody complicit or resistant types when few, if any, are able to practice hegemonic masculinity. Furthermore it's questionable whether hegemonic masculinity holds regulatory force when existing only as an unachievable ideal. A psychological account concerning the negotiation of gender subjectivity must be considered (Wetherell and Edley 1999). This should explain how social norms are (re)produced through compliance, or resistance, in everyday interaction (Wetherell and Edley 1999; Whitehead 1999).

A discursive approach, emphasising the importance of language in the (re)production of meaning, might aid the theoretical development of the concept (Whitehead 1999). A number of attempts have been made to understand masculinity using this approach (Speer 2001). In particular, Wetherell and Edley (1999) consider how men's gender identity is constituted through discursive practices, building upon previous work (Edley and Wetherell 1996) where they identify the worth of understanding masculinities as informed by societal discourses (Speer 2001).

These authors suggest that hegemonic masculinity operates at a macroand micro-level. At the macro-level, it is seen to comprise a set of preexisting discourses in society. Alternatively, at a micro-level, it is described as individual discursive positioning within these discourses. Wetherell and Edley (1999) extend our understanding of the latter through the notion of imaginary positions. This explains how masculinity is achieved psychologically. It refers to a process in which individuals adopt subjectivities relative to discourses of hegemonic masculinity, through situated psycho-discursive practices. These positions are 'imaginary' in that, although they serve as the basis for identity, they are constantly discursively re-instantiated. Self-positioning merely exists as a discursive strategy in which multiple meanings of masculinity are selectively drawn upon, according to the vagaries of the interactional context. Thus, individual men should not be labelled as particular character types, for example, complicit or subordinate (Wetherell and Edley 1999). Rather they 'can adopt hegemonic masculinity when it is desirable; but the same men can distance themselves strategically from hegemonic masculinity at other moments' (Connell and Messerschmidt 2005: 841). Situated discursive practices determine how men position themselves at any time, and hence the extent to which they consider themselves, or are described by others, as achieving the masculine ideal. This accounts for those seemingly contradictory occasions in which men simultaneously appear complicit with, as well as resistant to, hegemonic norms (Wetherell and Edley 1999). The banality of gender suggests that these practices are often unconscious. But, at times, they may also be consciously and deliberately deployed.

Although Connell and Messerschmidt (2005) reject the criticism levelled by discursive psychologists that the original formulation of hegemonic masculinity emphasises overarching structures and ideology 
to the detriment of individual agency, they do acknowledge the value of discursive theorising as it accounts for plurality and contradiction in men's subjectivities. Men are seen to strategically adopt these within situated interaction (Connell 2002). The multiple meanings associated with hegemonic masculinity are also far from problematic when viewed from this perspective, in that numerous related societal discourses are seen to give rise to them (Connell and Messerschmidt 2005).

Connell and Messerschmidt (2005) go on to argue that hegemonic masculinities may be studied empirically at three levels: local, regional and global. Local masculinities are constructed through face-to-face interaction, regional masculinity/ies are constructed at a cultural or societal level, and global masculinity is constructed in transnational settings such as politics, business and media. These three levels are interlinked and reciprocally inform each other. A 'geography of masculinities' goes some way to resolve the appearance of multiple hegemonic masculinities that simultaneously appear independent and interlinked. The meanings associated with local hegemonic masculinities always converge to a degree. This results from their shared representation in a single regional model, as well as their common constitution in relation to women's gender practices. It is clear that global masculinity has power to shape those at a regional and local level. However, it is important not to overemphasise the extent to which this is the case. Regional masculinities have an ability to resist and inform the global (Connell and Messerschmidt 2005). This study specifically considers how local and regional representations of hegemonic masculinity are (re)produced, and how men's gender identities constituted, through situated interaction. An attempt is made to account for complexity and diversity in this sense-making across intersecting social categories such as ethnicity and social class. Discourse analysis facilitates study into regional and local representation. It also describes local practices in which individuals discursively position themselves in relation to a shared understanding of the regional ideal.

\section{Exploring masculinities through discourse analysis}

Talking to South African men

Ten focus groups were held within the Cape Town metropolitan area. There were approximately six men in each group. An attempt was made to recruit men with varied life experiences in order to achieve multivocality or diversity of perspective. Community gatekeepers facilitated access to participants. Individuals were sampled and grouped on the basis of their ethnicity, as determined by spoken home-language and self-defined 'race', and social class, as established by attained education level. Ethnic categories consisted of Xhosa-'black', Afrikaans-'coloured', English- 
'coloured,' Afrikaans-'white’ and English-'white'. Attained education levels incorporated primary, secondary and tertiary. Age was not included as a formal sampling criterion. Nevertheless an attempt was made to involve men of diff erent ages in each group. Participants ranged between the ages of 17 and 70 and averaged 32 years of age. Sexuality was likewise not formally sampled, partly due to sensitivities concerning its disclosure.

Focus groups were an appropriate method for data gathering in the current study for two reasons. Firstly, analysis is partly informed by the rhetorical perspective. Data emerging from group discussion is particularly useful when adopting this perspective (Billig 1998). Secondly, this study embraces a feminist research agenda. Focus groups are said to diminish the power imbalance between the researcher and the researched; to reduce the extent to which the researcher imposes her/his interpretation in the research encounter; and play a potentially positive role in raising critical consciousness among participants (Wilkinson 1998).

Focus groups are sometimes criticised for producing manufactured data. Yet they arguably provide a useful sketch for analysis, where meaning is actively and collaboratively (re)produced through participant interaction. It is recognised that facilitators contribute to the (re)production of meaning through directing discussion toward a topic, and by attending to specific concepts. In this sense data is manufactured. But the purpose of focus group research is neither considered a 'fact-finding mission,' as may be the case in their more traditional use, nor a more 'pure' examination of meaningmaking through the analysis of 'naturally' occurring social interaction. Rather, focus groups are argued to provide rich and often unexpected data concerning a topic of interest. They allow researchers to ask what participants are doing, as well as to examine the broader representations they draw upon, in specific interactional contexts. Crucially, these contexts are considered specific, but no more so than any other, including the so-called 'naturalistic' (Edley and Litosseliti 2010:157).

The focus group procedure made use of three materials: 24 photographic cues selected so as to represent a broad range of masculinities across intersections of age, 'race' and social class, and serving as a pre-verbal aid to participant discussion; six vignettes developed in order to represent notions of 'sexuality', 'toughness', 'independence', 'status', 'responsibility' and 'homophobia' which are argued to represent dominant norms of masculinity in contemporary SA (Luyt 2003; 2005); and a semi-structured interview schedule. These materials were included on the understanding that focus groups require active verbal participation from members and some degree of standardisation across groups. Individuals diff er in their exposure to discussion of abstract concepts such as masculinities in SA. It was anticipated that these materials would encourage group debate. 
Whilst these prompted debate, care was taken to off er a safe environment which facilitated the emergence of issues beyond those introduced by the materials. Discussion was therefore more than simply an artefact of the prompts used, and reflected active negotiation between group members.

Three men facilitated focus group discussion. Each was assigned groups that were of their home language and 'race'. This was considered necessary in order to encourage unhindered discussion. Both assistants had graduate training and experience in social scientific fields. This included gender studies. Various additional steps were taken to ensure their requisite knowledge of both the research topic and focus group methodology.

Group discussion lasted between $1 \frac{1}{2}$ and 2 hours. This took place at suitable locations and at times amenable to all participants. These locations included a range of community venues, such as scout and school halls. Participants were made aware of standard ethical issues, including their anonymity, the confidentiality of data and their right to withdraw from the study. Furthermore, groups were informed that discussion would be recorded through the use of video- and audio-recording equipment.

Participant debate was transcribed in full, providing a comprehensive and permanent data record. The analysis undertaken in this study describes discourses at a macro-level as well as their (re)production through micro-level rhetorical devices. It may be argued that a study including a focus on such devices necessitates a detailed transcription method (Potter and Wetherell 2001; 2005). However, a highly comprehensive method such as Je ffrsonian transcription (Jeff erson 1984) was deemed inappropriate. The chosen transcription method was intentionally simple to avoid confusion during the complicated translation process. Some detail was nonetheless included, for example, inaudible discussion and interruptions, in order to maximise the fullness of the text within existing practical constraints (Billig 1998). Although the more traditional conversation analytically oriented reader may be disappointed, it is felt that micro-level analysis did not suff er as a result, given the use of the rhetorical devices introduced below. Indeed, overly fine-grained analysis is debatably inappropriate when applied to data that has undergone translation as a result of the added layer of interpretation that this involves.

The researcher is an English-speaking, heterosexual, 'white' South African, who has obtained a tertiary level of education. Therefore, where required, transcripts were reproduced in English through the procedure of back-translation (Brislin 2000). This procedure attempts to achieve what has been described as lexicon equivalence, in which importance is placed on both the linguistic and semantic features of the text (Neuman 1997; Swartz 1998). Facilitators participated in the translation of their respective focus groups. They did so along with others who were fully bilingual, as well as familiar with the sociocultural norms of each group. 
Developing a discourse analytic technique

A technique of discourse analysis was applied in this study. A discourse may be 'defined as a particular way of talking about and understanding the world (or an aspect of the world)' (Jørgenson and Phillips 2002: 1). This understanding is socially mediated (Paechter 2001). Discourses exist as nebulous patterns of meaning and are characterised by contradiction and fragmentation (Gavey 1997). They are shaped by, and simultaneously shape, broader ideological structures. These structures serve to maintain inequalities in power and privilege in society (Fairclough 1995; Woo ffi 2005). They do so through informing how social institutions, styles of thinking, individual subjectivity (Gavey 1997), and bodies are (re)produced (Paechter 2001). Discourse analysis attempts to identify such patterns of meaning through detailed linguistic examination of texts. These texts may include transcripts of naturally occurring conversations or interviews, existing documents or records and even descriptions of more general social practices (Gavey 1997). Patterns of meaning are informed by interrelated textual extracts. These allow discourse analysts 'to show systematic links between texts, discourse practices, and socio-cultural practices' (Fairclough 1995: 17). In describing discourses, the analyst is able to distinguish discursive resources and practices that individuals use in order to construct an understanding of their world (Gavey 1997) and how these make wider ideologies appear real (Potter and Wetherell 2001). Current discussion will focus on issues of importance to an approach known as discursive psychology (Edwards and Potter 1992). Diff erent theoretical approaches such as rhetoric, ethnomethodology, conversation analysis and post-structuralism have contributed to its development (Ballinger and Payne 2000).

Discourse analysis is applied diff erently within discursive psychology depending upon its specific theoretical orientation. Edley and Wetherell (1997; 2008) usefully distinguish between top-down and bottom-up approaches to analysis. The top-down approach draws heavily on the work of theorists such as Foucault (1978) and Marx (1867-1894; 1981). It focuses on broad concepts such as ideology and power in order to explore how individuals are constituted or positioned through discourse. Analysis primarily seeks to explore how inequality is maintained through describing dominant discourses (Ballinger and Payne 2000). Emphasis is placed upon the 'distal context'. This includes the broader background features of talk/ text, such as the participant's age, ethnicity, 'race' and social class; the sites in which talk occurs; and the sociocultural and ecological milieu in which it is embedded (Wetherell 2001).

Alternatively the bottom-up approach is informed by the work of theorists such as Sacks (1964-1965, 1992) and Garfinkel (1967). It is 
arguably the dominant approach in discursive psychology at present (Jørgensen and Phillips 2002). Fine-grained analysis of textual features is undertaken in order to describe the action-orientation of talk/text (Edley and Wetherell 1997; 2008). Austin (1962) was the first to identify 'talk as action. He argued that language not only carries meaning but also force. That is to say, individuals are able to do and achieve things through the use of language. This suggests that analysis should focus on what individuals are accomplishing through talk (Wood and Kroger 2000). Systematic analysis primarily seeks to describe the features of talk/text and, in so doing, explain their function (Ballinger and Payne 2000). It therefore focuses on the 'proximate context.' This includes characteristics of the actual interaction, such as participant understanding surrounding the type of conversation to which they are contributing, the actions made possible through sequences of talk and the roles that participants are assigned or assume (Wetherell 2001).

Thus, a clear tension exists between the top-down approach to discourse analysis, which focuses on broader social and political processes, and the bottom-up approach that focuses on the action accomplished by language use. The current study argues that a combined, or hybrid approach, as applied by Edley and Wetherell (1997) and convincingly recommended by Edley and Wetherell (2008), may well be preferable. The strength of this approach, specifically with respect to this study, is that it 'can not only appreciate gender as a discursive resource, but one that can also understand how discourse shapes people's sense of themselves (and others) as gendered beings' (Edley and Wetherell 2008: 166). As such, it facilitates exploration into how local and regional representations of hegemonic masculinity are (re)produced, through attending to diff erences in its construction across social categories such as ethnicity and social class, as well as considering how men's gender identities are accomplished in situated interaction.

It is important to recognise that a combined approach does not resolve the tension between top-down and bottom-up approaches to analysis. However, it does seek to manage it and, in so doing, account for the fact that individuals are at the same time both the products and the producers of discourse. Discursive psychologists are increasingly adopting this approach (Wilkinson 2001), albeit with diff erent emphases on top-down and bottom-up processes.

The analytic procedure adopted in this study was informed by the existing literature. This incorporates the fundamental assumptions of discourse analysis, as well as important concepts outlined by the rhetorical perspective (Billig 1987). New analytic concepts are also included. It is argued that these usefully extend existing theory. The rhetorical perspective suggests that hegemonic and subordinate discourses ${ }^{2}$ emerge respectively through the processes of categorisation and particularisation. Hegemonic discourses largely appear as stable categories of meaning, but may be 
disrupted and exposed to controversy through the process of particularisation. Consequently, subordinate discourses emerge to challenge them. In such conditions of controversy, individuals justify or criticise discourses in order to persuade an audience of their position. In this study the position participants choose to support concerns either the traditional construction of heteronormative masculinity, or an alternative one. However, it is argued here that individuals are doing more than just simply rejecting or supporting a position when they engage in justification and criticism. Luyt (2003: 57) has distinguished between 'normative reform' and 'normative revolution' Normative reform is understood as a specific form of criticism. It is directed against a hegemonic discourse, and holds the seeds for future critical challenge'. This 'diff ers from outright normative revolution where challenge to dominant conceptualisation would find direct confrontation' through the justification of a subordinate conceptualisation. Analytic subtlety can be developed further through the introduction of two additional concepts: normative preservation and normative (re)production. The first may be understood as a form of justification in support of a hegemonic discourse. The second is best described as a form of counter-criticism. It is directed against a subordinate discourse and serves one of three functions. It may act to (a) challenge, but not reject, the subordinate discourse; (b) reject the subordinate discourse, but in so doing, not completely support the hegemonic discourse; and (c) reject the subordinate discourse and, in this manner, off er complete support for the hegemonic discourse. Normative reform, revolution, preservation and (re)production might usefully be described as norm-referencing rhetorical devices. Such devices serve to warrant the factuality, reality or truth of the discourses they construct. Other common rhetorical devices applied in research include, for instance, 'category entitlements', 'empiricist accounting' and 'vivid description'. In addition to applying norm-referencing rhetorical devices in order to map broader patterns of discursive justification or criticism, this study also provides detailed rhetorical analysis of talk/text through the use of more conventional devices such as extreme case formulations, consensus claims and contrast (Edwards and Potter 1992:160-162) or differentiation.

There are no set procedures for undertaking discourse analysis (Billig 1998). Yet textual coding is frequently mentioned as a necessary preliminary stage. This seeks to reduce the density of text by sorting it into broad categories (Billig 1998; Potter and Wetherell 2001) in an 'inclusive and cyclical' process (Potter 1998: 239). An iterative inductive-deductive coding strategy was initially adopted in order to identify broad patterns of meaning. The traditional discourses of masculinity around which discussion had been focused through the aid of vignettes, provided an initial means through which to understand data. This understanding progressively developed through a commitment to inductive processes, where patterns of meaning were identified through interrelated textual extracts. As in 
other rhetorically guided studies (e.g. Radley and Billig 1996), turn-taking sequences (Hutchby and Wooffitt 1998) served as the unit of analysis.

The coding process contributes only partially to analysis. Indeed some discourse analysts go so far as to claim that it should not be considered part of the actual process of analysis (e.g. Potter 1998; Potter and Wetherell 2001). More fine-grained analysis of text takes place during the writing phase of the report and is evident in the presentation of findings. It is important to stress that no analysis is ever definitive (Billig 1998). The results presented here are no exception.

The current paper considers a single discourse and related participant subject positioning that emerged through in-depth analysis: heteronormativity. This may be described as a dominant discourse of regional hegemonic masculinity. Particular emphasis is aff orded its underlying traditional/alternative discursive practices of 'performative/intimate (hetero)sexuality' and 'homosexual rejection/acceptance'. The way in which these practices are constructed diff ers across sociocultural groups, giving rise to local hegemonic masculinities. Yet their shared constitution in the regional discourse suggests, as is the case in Western society, that sexuality exists as a common axis along which hegemonic and subordinate masculinities are distinguished in contemporary SA society. It seems appropriate therefore to consider the two discursive practices underlying the discourse of heteronormativity.

\section{Findings}

Discursive practices of 'homosexual rejection' and 'homosexual acceptance'

Homosexual rejection, or homophobia, may be described as an act of Othering. Individuals are able to secure an identity and reputation as 'real' men through distancing themselves from subordinated homosexuals (Hearn 2004; Reeser 2010). Connell (1992: 736) succinctly observes that 'antagonism toward homosexual men may be used to define masculinity'. This understanding is supported through countless research studies (e.g. Cameron 1997; Gough and Edwards 1998). Participant discussion revealed support for the traditional discursive practice of homosexual rejection as well as the alternative discursive practice of homosexual acceptance.

Traditional discursive practice of 'homosexual rejection'

The traditional discursive practice of homosexual rejection surfaced frequently, although not exclusively, in discussion concerning vignette 3 . This vignette presents a hypothetical scenario in which 'Bongani' unexpectedly finds his son 'Thandu' kissing another man. He is with his friends at the time, but chooses not to tell any of them what he has just seen: 
Extract 1: (Xhosa-'black' men with secondary education)

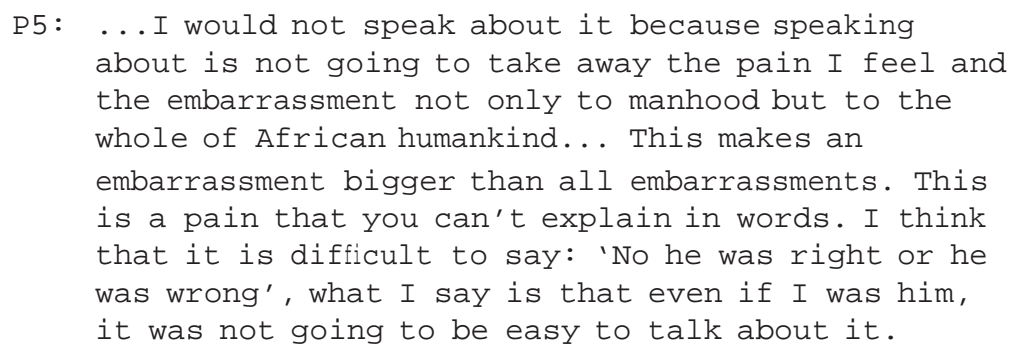

Focus Group UB1

Participant 5 supports the hegemonic discursive practice of homosexual rejection. His support for this and its construction as normative, is asserted through a number of extreme case formulations (Pomerantz 1986), for example, 'bigger than all embarrassments' (l. 5) and 'the whole of African humankind' (ll. 3-4). He also positions himself within it by stressing that his son's supposed homosexuality would be shaming to the extent that he would find it di ffilt to 'talk about it' (l.9) with friends, and it would cause pain he was unable to 'explain in words' (l. 6). The co-construction of real 'manhood' (1.3) and heterosexuality is also evident here. But what is particularly interesting is his association between this and 'African' (l. 4) culture. An implicit contrast, or 'strategy of diff erentiation' (Edley and Wetherell 1997: 209), is therefore made between 'real' heterosexual African manhood and other non-African homosexual masculinities. Homosexuality appeared taboo among Xhosa participants to the extent that at times they were found to resist suggestion of its existence:

Extract 2: (Xhosa-‘black’ men with secondary education)

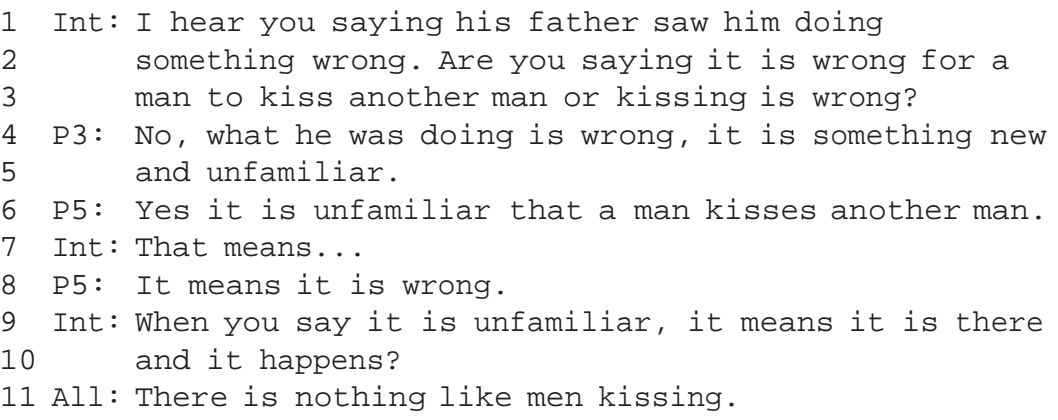

Focus Group UB1

The interviewer introduces an alternative discursive resource, seen in the suggestion that homosexuality 'is there and it happens' (ll. 9-10), 
which challenges the discourse of heteronormativity. In response, participants off er a terse extreme case formulation that 'there is nothing like men kissing' (l. 11). This signals their disapproval of the practice, reinforces the co-construction of 'real' masculinity and heterosexuality, and also again implicitly contrasts African culture from problematic or 'wrong' (l. 8) Other homosexual cultural practice. That is to say 'it is something new and unfamiliar' (ll. 4-5). Their identity claim to 'real' heterosexual African manhood is thus collectively (re)instantiated. Literature, however, suggests that homosexuality is not as alien as these men suggest. For example, evidence indicates that male-male sexuality has a long and continuing history among the Basotho, even though they are often characterised as macho and ardently heteronormative in comparison to other cultural groups in southern Africa (Epprecht 2002). Even so, the occurrence of homosexuality is popularly considered rare if not non-existent among 'black' Africans. The African nationalist movement encourages this thinking, arguing that such behaviour is 'un-African' and merely an imported European phenomenon. Growing regional African nationalism is therefore complicit in perpetuating homophobia among 'black' Africans, where a positive and idealised postcolonial African identity position is constructed against an imagined 'white' Other. In this respect, it is ironic that homophobia may in actuality be considered the true European import (van Zyl 2011). However, this hegemonic discursive practice was not only justified through appeals to culture. Normative preservation was achieved diff erently across groups:

Extract 3: (English-'coloured' men tertiary education)

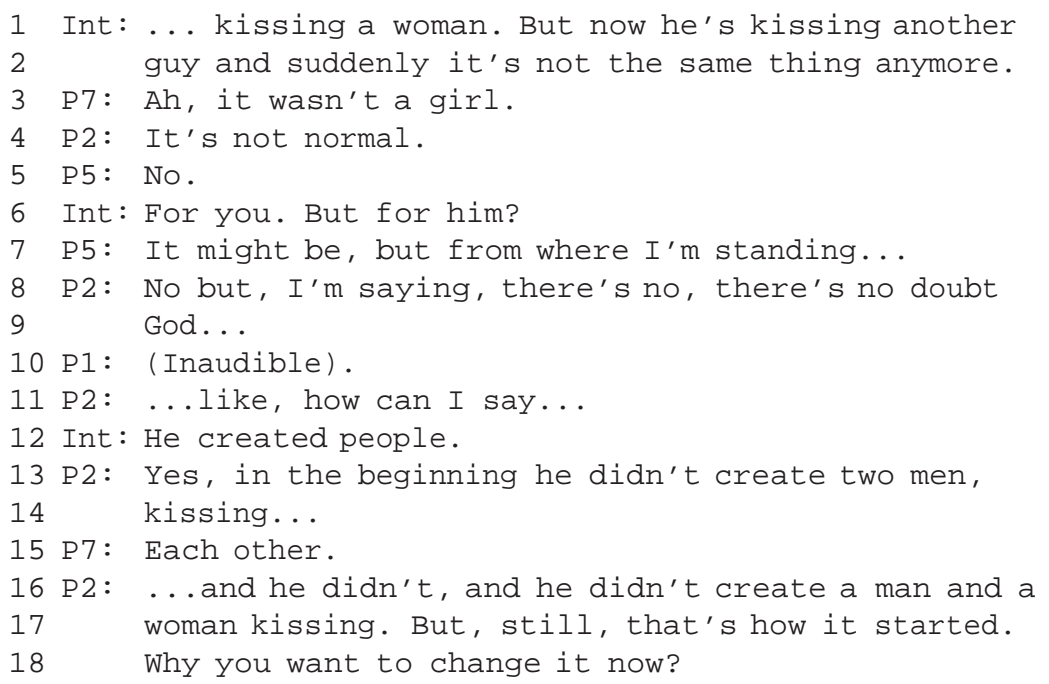


In the extract above, identity work is being accomplished both explicitly and implicitly. Participant 5 explicitly positions himself within the discourse of heteronormativity, recognising that there 'might be' alternatives but not from 'where (he's) standing' (l. 7). Participant 2 likewise suggests that homosexuality is 'not normal' and therefore implicitly positions himself within this discourse. Disapproval of homosexuality is justified on theological grounds. '(I)n the beginning, he claims, God 'didn't create two men' (l. 13) but rather 'a man and a women' (ll. 16-17). Homosexuality is therefore inappropriate in that it transgresses the divine ordinance of heterosexuality. It is relevant to note that theological justification emerged within interaction which was situated in a community church to which group members belonged. Wetherell (2001) highlights the importance of the distal context, such as the site in which talk occurs, when interpreting data. The normality of homosexuality is similarly thrown into question in extract 4:

Extract 4: (English-‘white’ men with tertiary education)

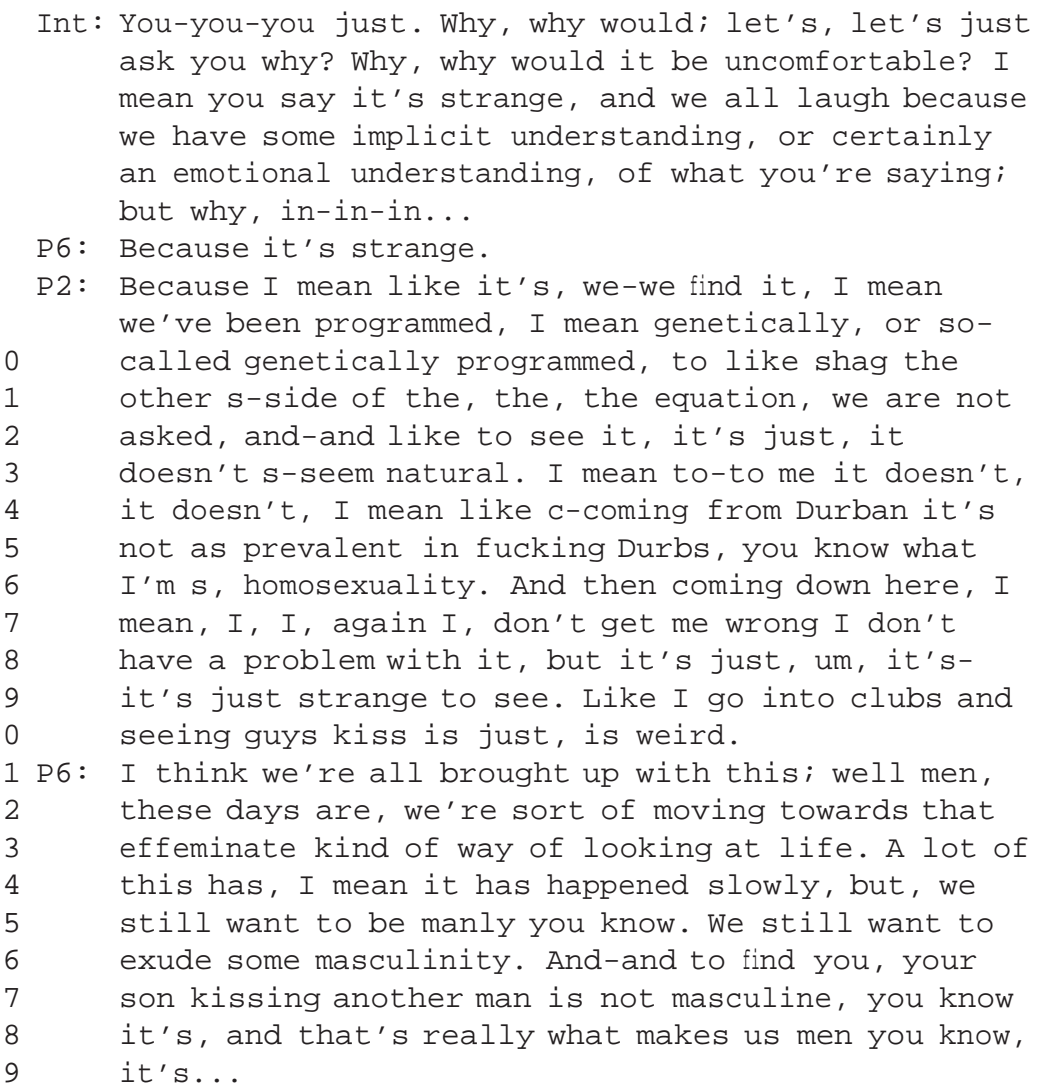

Focus Group UC5.2 
In this case participants do not justify their disapproval of homosexuality on the basis of a cultural (e.g. extract 1 and 2) or theological argument (e.g. extract 3), but rather a scientific one. Again, the interactional context appears related to the chosen justification. Discussion took place within a university setting among commerce students. Participant 2 suggests that it 'doesn't seem natural' given that 'we've been programmed... genetically' to have sex with females who are 'the other s-side of the, the, the equation' (ll. 10-11). However, he anticipates criticism through the disclaimer 'don't get me wrong I don't have a problem with it, but it's just' (ll. 17-18). He then moves on immediately to justify his position so as to inoculate himself against accusations of prejudice. The participant underlines he is particu- larly unaccustomed to homosexuality having recently moved to Cape Town ${ }^{3}$ from Durban. As such, it is not that he is homophobic, but rather because homosexuality appears 'strange' (l. 19) to him. In doing so, he positions himself within the discourse of heteronormativity.

Participant 6 likewise supports and positions himself within this discourse. This follows initial resistance seen in his non-elaborative response - '(b)ecause it's strange' (l. 7) - to the alternative discursive resource made available by the interviewer who questions why homosexual practice would make men feel 'uncomfortable' (l. 2). This questioning again acts to challenge the discourse of heteronormativity. The participant later suggests that 'we're sort of moving toward that eff eminate kind of way of looking at life' (ll. 2-23) but despite this still have a need 'to be manly' (l. 25). Consensus in this position, and hence its implied factuality, is claimed through the use of words such as 'we' (l. 24) and 'us' (1. 28). In essence he invokes a rehearsed argument that links eff eminacy, homosexuality and masculinity (Gough and Edwards 1998; Martino 2008). Connell (1992: 736 emphasis origina) explains that '(t)o many people, homosexuality is the negation of masculinity, and' because femininity is also considered masculinity's opposite 'homosexual men must be eff eminate'. It is interesting to note that the participant chooses not to suggest that it is heterosexuality '(that) makes us men' (1. 28). This underlines the observation that heterosexuality acts as a compulsory but hidden social norm (Kitzinger 2001; Rich 1980). Thus, any direct mention of heterosexuality is absent. Homophobia alone adequately marks hegemonic masculinity. Given such staunch support for the hegemonic discursive practice of homosexual rejection, it may seem incongruous to suggest that this participant in fact engages in a process of normative reform, albeit unintentionally. He makes a discursive resource available for the critical (re)negotiation of masculinity through appreciation that notions of masculinity are 'sort of moving' (1. 22) rather than remaining static. This is not, however, taken up by other participants.

Alternative discursive practice of 'homosexual acceptance'

In extract 5, the interviewer asks the group whether they could expect a 'negative reaction from others', if their son were found to be homosexual. The alternative discursive practice of homosexual acceptance emerges through participants 2's response. He claims that there is little overt prejudice against homosexuality in society:

Extract 5: (English-‘white’ men with tertiary education) 


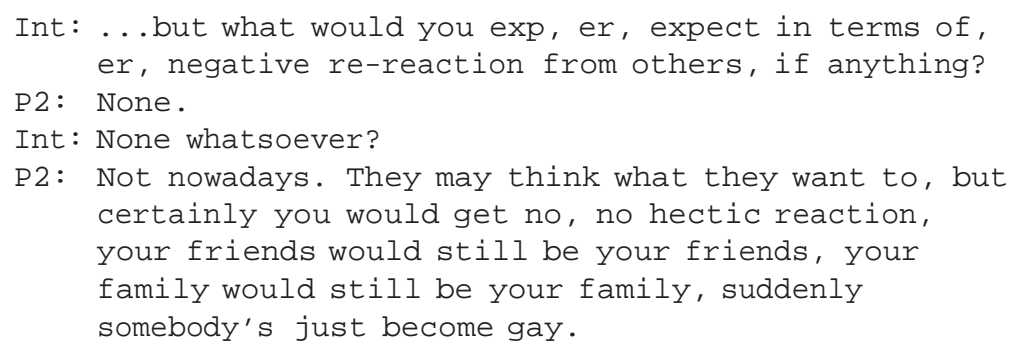

Focus Group UC5.1

The participant justifies the subordinate discourse, arguing that homosexuality would receive 'no hectic reaction' (l. 6) from others 'nowadays' (l. 5), and therefore presents the case that there has been a successful normative revolution. The discursive practice of homosexual rejection is claimed to have been displaced by homosexual acceptance. Yet the participant's resistance to the alternative discursive resource made available by the interviewer, who suggests that 'negative re-reaction from others' (l. 2) to homosexual practice still occurs, is seen in his short and swift extreme case formulation - 'none' (l. 3). This implies that despite his rhetorical strategies, he is aware of homophobia in society. He confirms this later by accepting individuals 'may think what they want to' (l. 5) but are expected to censor their prejudice. His argument was also challenged by others:

Extract 6: (English-'white’ men with tertiary education)

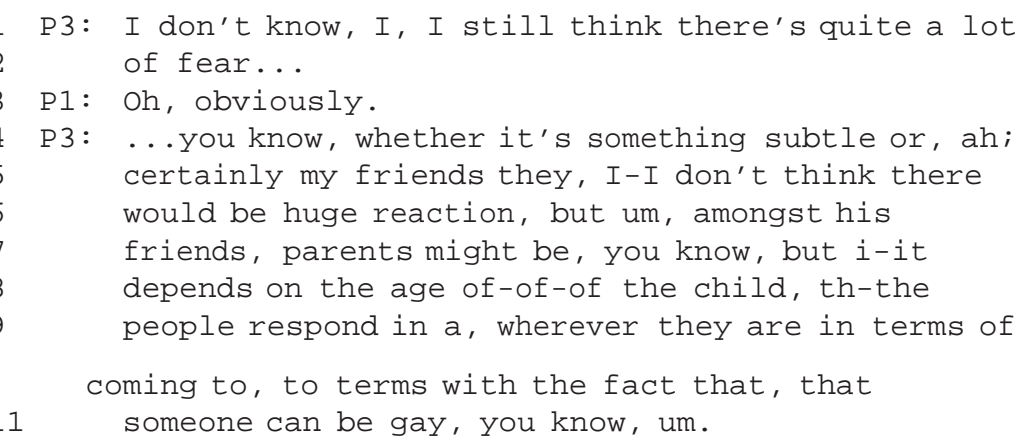

Focus Group UC5.1

Participant 3's response off ers an interesting example of identity work. He accepts the subordinate discursive practice of homosexual acceptance, and clearly positions himself within it. Moreover, its factuality is implied by supposed consensus in this position. That is to say, among his 'friends' (1.5). However, he criticises participant 2's suggestion that such acceptance is now dominant. He argues, through a strategy of diff erentiation, that there is still 'quite a lot of fear' (ll. 1-2) and that cultural diff erences will determine the extent to which there is a negative reaction from others. That is to say, a comparison is made between his friends and Bongani's 'friends' and 'parents' (l. 7), who presumably diff er along sociocultural lines. He is therefore making a distinction between himself/his friends, presumably 'white' English men, who are tolerant, versus intolerant 'black' people. Nonetheless, participant 3 seems to be aware of the fact that he 
making potentially controversial racial claims, as evidenced by the number of repetitions and insecurities in lines 6 to 11 .

Discursive practices of 'performative (hetero)sexuality' and 'intimate (hetero)sexuality'

The notion of performative (hetero)sexuality is often identified as an important characteristic of hegemonic masculinity (Boyarin 1997; Donaldson 1993). This 'encourage(s) men to be sexually assertive, be always ready to have sex, view sex primarily as pleasurable and recreational, perceive penetration as the goal of sex, control all aspects of sexual activity, and have multiple sex partners' (Bowleg 2004: 169). Research evidence supports this notion (e.g. Allen 2003; Grazian 2007). Performative (hetero) sexuality emerged as a traditional discursive practice in this analysis. An alternative conceptualisation surrounding intimate (hetero)sexuality also materialised. This highlighted the importance of emotional intimacy over physical performance and pleasure in heterosex. Few research studies observe intimacy as related to the practice of traditional masculinity (e.g. Rogers 2005).

Traditional discursive practice of 'performative (hetero)sexuality'

The traditional discursive practice of performative (hetero)sexuality was often, although not only, evident in discussion concerning vignette 5. Participants were asked to discuss a scenario in which 'Henk' had been unable to achieve an erection during a sexual encounter with 'Sara' A high degree of agreement characterised group discussion where it was frequently argued that failure to perform 'degrades your manliness' (l. 5). The co-construction of 'real' masculinity and performative (hetero) sexuality is obvious here:

Extract 7: (English-'coloured' men with secondary education)

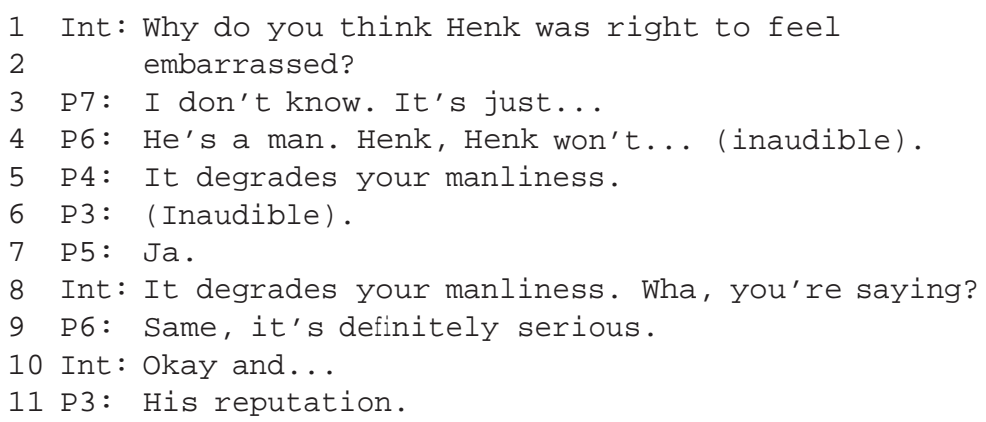

Focus Group UB3

Participants in this extract preserve the discursive practice that men should perform during heterosex. To fail is 'definitely serious' (l. 9). Participant 3 justifies this position by suggesting that Henk's 'reputation' (l. 11) would suff er as a result of his failure. Reputation rests upon normative assumptions concerning the relationship between masculinity and performative (hetero)sex. It entrenches the importance of this relationship among men. Bartky (1990: 72) notes:

In contemporary patriarchal culture, a panoptical male connoisseur resides within the consciousness of most women: They stand perpetually 
before his gaze and under his judgement. Women lives her body as seen by another, by an anonymous patriarchal Other.

Similarly men find themselves exposed to the gaze of others. Women, as defined by the gender order, reside within each man's consciousness. This serves a self-regulatory function. This is evident in participant 5's imagined situation in extract 8, where, if he failed to get an erection during sex 'it becomes obvious to her there is a problem about you, when the problem starts you lose confidence and your manhood' (ll. 25-27):

Extract 8: (Xhosa-‘black’ men with primary education)

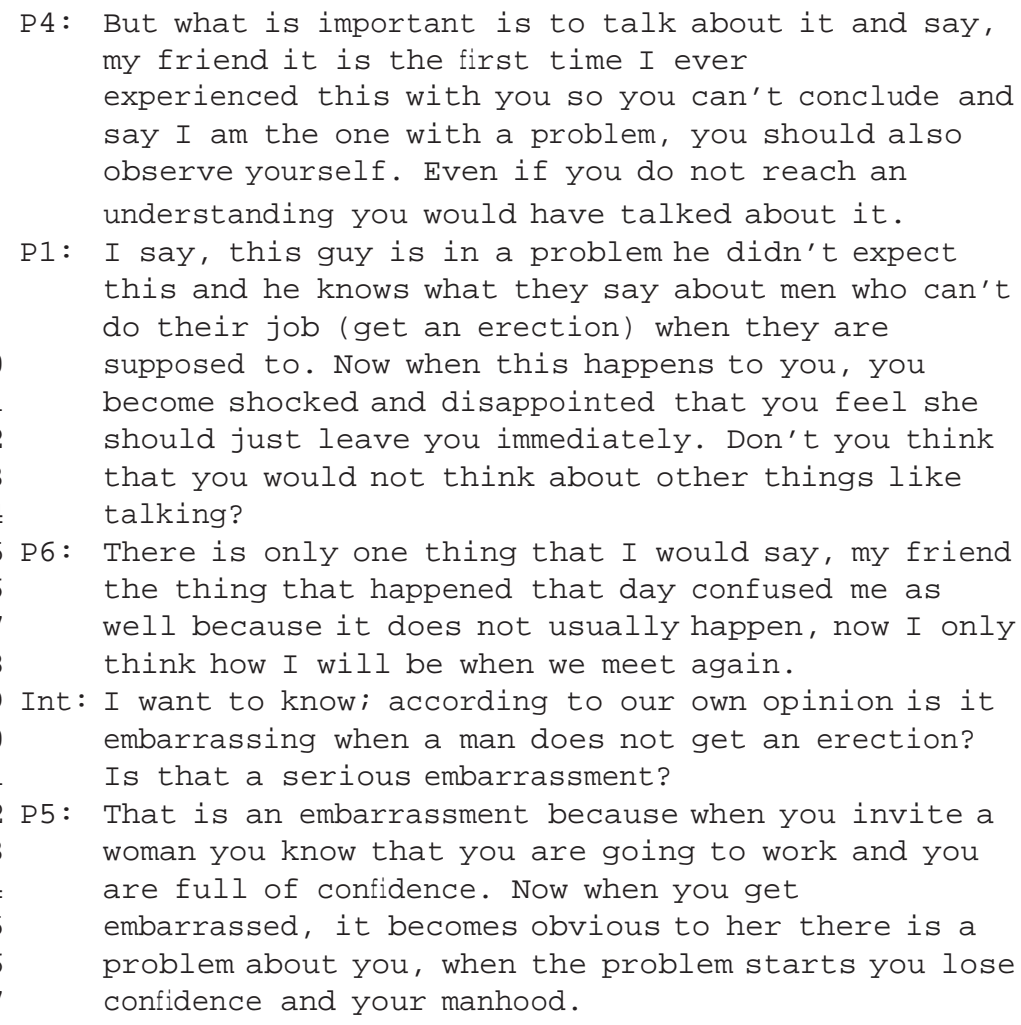

Focus Group UA1

The participant argues that 'when you invite a woman' (ll. 22-23) to engage in sex, she expects erectile performance. To imagine anything but is an 'embarrassment' (l. 22). Masculinities undergo (re)production under an omnipresent system of patriarchal heterosexual surveillance. This acts upon the individual man. It encourages his practice of dominant gender discourse (Bartky 1990) and related gender identity positioning.

Nonetheless normative reform was evident in a limited number of cases. Participant 4 criticises the common suggestion that men 'should just leave' (l.12) when they are unable to perform during heterosex. He argues that at the very least it 'is important to talk about it' (l. 1) with the woman. This discursive resource made available by participant 4 holds the potential to challenge the dominant discursive practice that equates 'your manhood' (l. 27) to your (penis) 'going to work' (1. 23).

Despite the potential for future critical challenge made possible through the willingness to enter into dialogue, participant 4 does not directly challenge the dominant discursive practice, but rather suggests that this 
may serve as a means by which the woman is forced to accept responsibility for the man's failure. It is argued that the woman 'should also observe (her) self' (ll. 4-5). Blaming the women for performative failure in heterosex emerged repeatedly in group discussion.Alternative discursive practice of 'intimate (hetero)sexuality'

Direct challenge to the hegemonic discourse occurred rarely. But instances of normative revolution did appear. Yet this most often took place among historically and materially privileged groups. It is fair to suggest that members of these groups have the greatest power to (re)produce alternative discursive resources that challenge the status quo. Most notably, in extract 9, participant 3 argued that emotional intimacy takes precedence over physical performance and pleasure in heterosex where the whole love aspect of it is very important' (ll. 5-6):

Extract 9: (English-'white’ men with tertiary education)

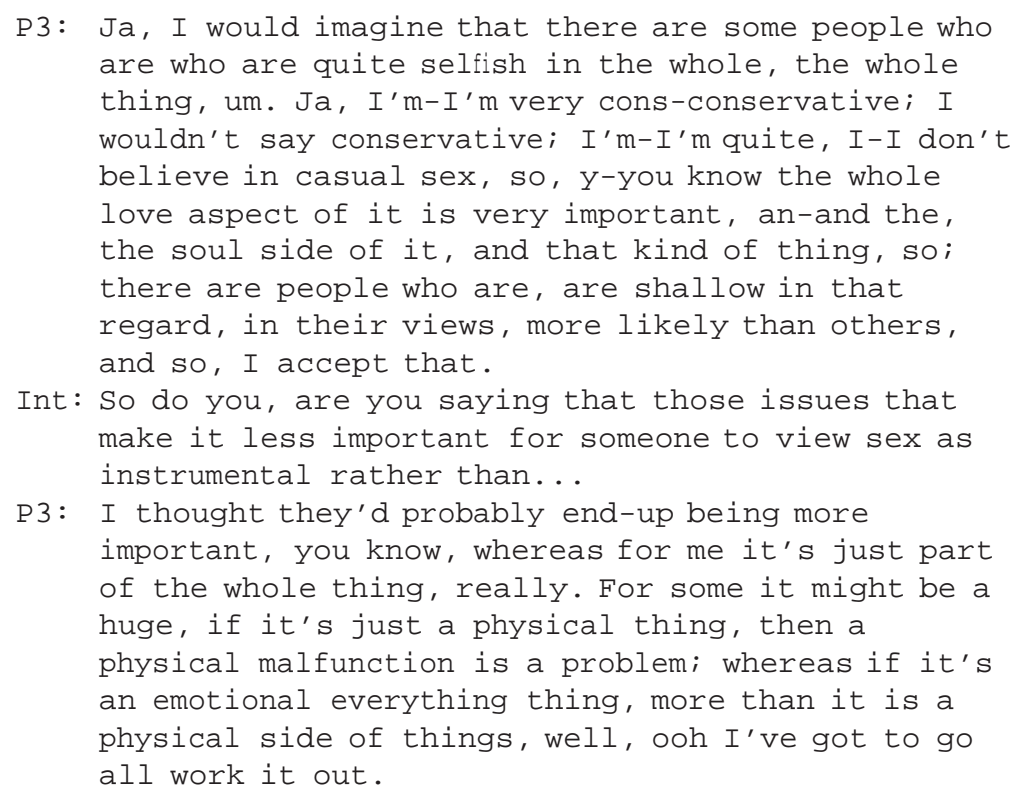

Focus Group UC5.1

The participant positions himself favourably within the discursive practice of intimate (hetero)sexuality through a strategy of diff erentiation. He argues 'that there are some people who are who are quite selfish in the whole, the whole thing' (ll. 1-3). He goes on to justify and hence warrant its factuality through two rhetorical strategies. Firstly, he draws upon the notion of conservatism in order to suggest that his position is safeguarding traditional and hence consensual and esteemed values. This is curious in that the present study, as well as the existing literature cited above, indicates that these values are, in fact, non-traditional. Secondly, he argues that individuals who consider performance and pleasure as overarching goals in heterosex 'are shallow' (1. 8). It is only for these individuals that 'physical malfunction is a problem' (l.18).

Finally, and more generally, it is interesting to note the extent to which participant discussion supports the previously noted observation that heterosexuality acts as a compulsory but hidden norm in society (Kitzinger 
2001; Rich 1980). Sex, for participants, implicitly referred to heterosex. This highlights the overlap between the traditional discursive practices of performative (hetero)sexuality and homosexual rejection. The heterosexual norm partly structures internal hegemony within society. Hegemonic masculinity is defined against subordinated homosexuality (Cheng 2007; Connell 1995).

\section{Conclusion}

This study describes the (re)production of local and regional representations of hegemonic masculinity, together with the constitution of men's gender identity through situated social practices. It points toward the importance of heteronormativity in defining hegemonic masculinity in SA, and examines how this is variably (re)produced in interactions among diff erent groups of men. This extends the existing literature (e.g. Cameron 1997; Kiesling 2006; Kitzinger 2006) seeking 'to understand how heteronormativity is produced and reinforced in everyday interactions' (Kitzinger 2008: 121) across societies.

The emergent discourse of heteronormativity was described. This, together with its underlying discursive practices of 'homosexual rejection' and 'performative (hetero)sexuality', constitutes a dominant discourse of regional hegemonic masculinity. Two further related alternative discursive practices were also described: 'homosexual acceptance' and 'intimate (hetero)sexuality' These practices may otherwise be described as contributing toward a subordinate discourse of regional hegemonic masculinity and thereby resisting the dominant definition of masculinity.

Discourse was defined as dominant in so far as it appeared taken for granted (Edley 2001) by most participants. In comparison, subordinate discourse appeared to di ffer that it was not taken for granted. Local hegemonic masculinities were variably informed by discursive practices, as well as by the arguments around which they were constructed. Diversity in local hegemonic sense-making emerged across intersecting social categories such as ethnicity and social class. Group comparison demonstrated this well. For example, in the analysis above, the discursive practice of homosexual rejection was justified variably on the basis of cultural, theological and scientific arguments by Xhosa-'black', English-'coloured' and English-'white' men respectively. Divergent support across social groups for discursive practices and their component arguments indicates some of the crisis tendencies currently being resolved among men in the SA gender order. For example, the challenge posed by ascendant 'black' African masculinity, constructing itself against an imagined inferior Other, yet marginalised in 'white' men's rhetoric. The interests of some men were also clearly privileged over others. The dominant discourses of masculinity tend to serve the interests of young heterosexual men who espouse a female sexual object choice and are best able to perform heterosex.

The results therefore confirm the notion that multiple hegemonic masculinities can exist. These occur at the local level and appear independent as well as interlinked. The meanings associated with local hegemonic masculinities converge to a degree as a result of their shared constitution in regional discourse. This accounts for complexity, contradiction and diversity in hegemonic discourse. But these features were also evident in situated social practice. Men's gender identities were continually (re)constituted through 
complex practices. More specifically, individuals were found to strategically adopt subjectivities within situated interaction. This was the case in, for example, extract 9. The participant positioned himself as conservative. This was somewhat contradictory in that it served to justify the subordinate and hence non-traditional discursive practice of intimate (hetero)sexuality. Yet, in justifying the subordinate discourse through this rhetorical strategy, he was able to legitimately position himself within it. Identities were therefore constituted through available discursive resources. Participants were most likely to position themselves within accessible local hegemonic representations. It is therefore important to stress the degree to which selfpositioning exists as a discursive strategy. Multiple meanings surrounding masculinity are selectively drawn upon according the vagaries of the interactional context. For example, in extract 3, the interactional context of a church likely contributed toward participants drawing upon theological justification for homosexual rejection. Contexts were largely defined in this study through homogeneous focus groups, pre-selected so as to represent a broad range of men in society, and defined on the basis of ethnicity and social class. These appear as particularly important axes of social di ffence in contemporary SA as evidenced in discussion. For example, as was evident in extract 9, direct challenge to the hegemonic discourse most often took place among historically and materially privileged groups (e.g. 'white' men with high levels of education) who have the greatest power to challenge the status quo. Masculinities therefore seemingly continue to be constructed around category diff erences that were salient in the country's past. This is clearly seen in the various strategies of diff erentiation employed by the participants.

A technique of discourse analysis that considers the rhetorical aspects

of text was adopted. This highlights the extent to which practices of both compliance and resistance contribute toward the (re)production of masculinities. Participants overwhelmingly engaged in complicit practices in support of the hegemonic discourse of heteronormativity. This was seen in numerous instances of normative preservation. But challenge to this discourse, seen in normative reform and revolution, was also evident in a limited number of cases, thus making change possible. This usefully exposes the complexity, contradiction, diversity and inherent tensions in hegemonic sense-making. The technique incorporates the fundamental assumptions of discourse analysis in addition to important concepts outlined by the rhetorical perspective. The description of the four norm-referencing rhetorical devices, namely normative preservation, reform, revolution and (re)production, arguably provides added theoretical subtlety and analytic strength, in addition to other more commonly applied devices. Lastly, the analysis sought to emphasise both macro- and micro-level analyses in order to highlight that individuals are both the products and the producers of discourse.

This study's greatest strength resides in its providing insight into how the notion of hegemonic masculinities may be reciprocally analysed socioculturally through discourse, and psychologically through subjectivity. Yet there are other aspects that deserve further attention. The study did not explore the psychic dimensions of gender identity (Jeff erson 2002). As suggested, this may include consideration surrounding whether gender identity is psychically divided and multilayered, and whether men experience tensions as a result of often complex and contradictory 
identities. Moreover greater consideration should surround the extent to which gender relations are (re)produced through discursive as well as material practices. The notion of embodiment remains a useful starting point in this regard (Connell and Messerschmidt 2005). Finally, few studies have considered the extent to which global masculinity shapes that at a regional and local level. Goswami's (2008: 344) concept of 'compulsory heteroimperial masculinity' serves as an interesting starting point for further study into the global (re)production of heteronormativity and hegemonic masculinities. More work should be undertaken in this area.

\section{Acknowledgements}

Research funds were made available through the Commonwealth Commission and Universities UK. Special thanks go to Malibongwe Gwele and Keith Ruiters for their assistance in focus group facilitation, transcription and translation; Ntutuzelo Tsotsi and Marelise van der Merwe for their help

in translation; Gloria Mabeka for her needed gatekeeping support; Jenny

Luyt for her encouragement; Cliff ord Stevenson for his useful suggestions; and all the men who agreed to take part in this research.

\section{About the author}

Russell Luyt is a senior lecturer in the Department of Psychology at the University of Winchester. He is particularly interested in identity processes as well as debates concerning research philosophy and qualitative methodology. His work is grounded within a critical perspective and has to date focused primarily on the social psychology of gender. This has included, for example, the critique of traditional masculinity, femininity and gender measurement; media representations; masculinities and aggression; as well as the intersection of gender and other social categories in SA. He is currently extending these lines of research and developing his interest in radicalisation among marginalised communities from a gender perspective.

\section{Notes}

1 The Union of South Africa originated through the amalgamation of the two Boer republics of the South African Republic (Transvaal) and the Orange Free State, as well as the two British colonies of the Cape and Natal, under a single system of government (see Beinhart 2001).

2 The concepts of 'dominant', 'hegemonic' and 'traditional discourses', as well as 'alternative' and 'subordinate discourses', are considered interchangeable in the current study.

3 Cape Town is considered as the 'gay capital' of Africa (see Visser 2003).

\section{References}

Allen, L. (2003) Girls want sex, boys want love: resisting dominant discourses of (hetero)sexuality. Sexualities 6: 215-36. http://dx.doi.org/10.1177/1363460703006002004

Austin, J. (1962) How to Do Things with Words. Cambridge, MA: Harvard University Press. 
Ballinger, C. and Payne, S. (2000) Discourse analysis: principles, applications and critique. British Journal of Occupational Therapy 63: 567-72.

Bartky, S. L. (1990) Femininity and Domination: Studies in the Phenomenology of Oppression. New York: Routledge.

Beinart, W. (2001) Twentieth-Century South Africa. Oxford: Oxford University Press

Billig, M. (1987) Arguing and Thinking: A Rhetorical Approach to Social Psychology. Cambridge: Cambridge University Press.

Billig, M. (1997) The dialogic unconscious: psychoanalysis, discursive psychology and the nature of repression. British Journal of Social Psychology36: 139-59. http://dx.doi.org/10.1111/j.2044-8309.1997.tb01124.x

Billig, M. (1998) Rhetorical and discursive analysis: how families talk about the royal family. In N. Hayes (ed.) Doing Qualitative Analysis in Psychology 39-54. Hove: Psychology Press.

Bowleg, L. (2004) Love, sex, and masculinity in sociocultural context: HIV concerns and condom use among African American men in heterosexual relationships. Men \& Masculinities 7: 166-86. http://dx.doi.org/10.1177/1097184X03257523

Boyarin, D. (1997) Unheroic Conduct: The Rise of Heterosexuality and the Invention of the Jewish Man. Berkley, CA: University of California Press.

Brislin, R. W. (2000) Back-translation. In A. E. Kazdin (ed.) Encyclopedia of Psychology 359-360. Washington, DC: American Psychological Association.

Cameron, D. (1997) Performing gender identity: young men's talk and the construction of heterosexual masculinity. In S. Johnson and U.H. Meinhof (eds) Language and Masculinity 4-64. Oxford: Blackwell Publishers.

Campbell, C. (1997) Migrancy, masculine identities and AIDS: the psychosocial context of HIV transmission on the South African gold mines. Social Science and Medicine 45: 273-82. http://dx.doi.org/10.1016/S0277-9536(96)00343-7

Campbell, C. (2001) 'Going underground and going after women': masculinity and HIV transmission amongst black workers on the mines. In R. Morrell (ed.) Changing Men in Southern Africa 275-86. Pietermaritzburg: University of Natal Press.

Cheng, C. (2007) Marginalized masculinities and hegemonic masculinity: an introduction. Journal of Men's Studies 7: 295-315. http://dx.doi.org/10.3149/jms.0703.295

Connell, R. W. (1987) Gender and Power: Society, the Person and Sexual Politics. Cambridge: Polity Press.

Connell, R. W. (1992) A very straight gay: masculinity, homosexual experience, and the dynamics of gender. American Sociological Review57: 735-51. http://dx.doi.org/10.2307/2096120

Connell, R. W. (1993) The big picture: masculinities in recent world history. Theory and Society 22: 597-623. http://dx.doi.org/10.1007/BF00993538

Connell, R. W. (1995) Masculinities. Cambridge: Polity Press.

Connell, R.W. (2002) On hegemonic masculinity and violence: response to Jeff erson and Hall. Theoretical Criminology 6: 89-99. http://dx.doi.org/10.1177/136248060200600104

Connell, R. W. and Messerschmidt, J. W. (2005) Hegemonic masculinity: rethinking the concept. Gender \& Society 19: 829-59. http://dx.doi.org/10.1177/0891243205278639

Cooper, A. (2009) 'Gevaarlike transitions': negotiating hegemonic masculinity and rites of passage amongst coloured boys awaiting trial on the Cape Flats. Psychologyin Society 37: 1-17.

Donaldson, M. (1993) What is hegemonic masculinity? Theory and Society 22: 643-57. http://dx.doi.org/10.1007/BF00993540

Donham, D. L. (1998) Freeing South Africa: The 'modernization' of male-male sexuality in Soweto. Cultural Anthropology 13: 3-21. http://dx.doi.org/10.1525/can.1998.13.1.3 
Edley, N. (2001) Conversation analysis, discursive psychology and the study of ideology: a response to Susan Speer. Feminism \& Psychology 11: 136-40. http://dx.doi.org/10.1177/0959353501011001007

Edley, N. and Litosseliti, L. (2010) Contemplating interviews and focus groups. In L. Litosseliti (ed.) Research Methods in Linguistics 155-79. London: Continuum.

Edley, N. and Wetherell, M. (1996) Masculinity, power and identity. In M. Mac-an-Ghaill (ed) UnderstandingMasculinities:Social Relationsand Cultural Arenas97-114. Buckingham: Open University Press.

Edley, N. and Wetherell, M. (1997) Jockeying for position: the construction of masculine identities. Discourse \& Society 8: 203-17. http://dx.doi.org/10.1177/0957926597008002004

Edley, N. and Wetherell, M. (2008) Discursive psychology and the study of gender: a contested space. In K. Harrington, L. Litosseliti, H. Sauntson and J. Sunderland (eds) Gender and Language Research Methodologies161-73. Basingstoke: Palgrave Macmillan.

Edwards, D. and Potter, J. (1992) Discursive Psychology. London: Sage Publications.

Epprecht, M. (2002) Male-male sexuality in Lesotho: two conversations. Journa/ of Men's Studies 10: 373-89. http://dx.doi.org/10.3149/jms.1003.373

Fairclough, N. (1995) Critical Discourse Analysis: The Critical Study of Language. London: Longman.

Foucault, M. (1978) The History of Sexuality. Trans. R. Hurley, Vol. 1. Harmonsworth: Penguin.

Garfinkel, H. (1967) Studies in Ethnomethodology. Englewood Cliff s, NJ: Prentice-Hall.

Gavey, N. (1997) Feminist poststructuralism and discourse analysis. In M. M. Gergen and S. N. Davis (eds) Toward a New Psychology of Gender 49-64. New York, NY: Routledge.

Goswami, N. (2008) Autophagia and queer transnationality: compulsory heteroimperial masculinity in Deepa Mehta's Fire. Signs 33: 343-69. http://dx.doi.org/10.1086/521052

Gough, B. and Edwards, G. (1998) The beer talking: four lads, a carry out and the reproduction of masculinities. Sociological Review46: 409-35. http://dx.doi.org/10.1111/1467-954X.00125

Grazian, D. (2007) The girl hunt: urban nightlife and the performance of masculinity as collective activity. Symbolic Interaction 30: 221-43. http://dx.doi.org/10.1525/si.2007.30.2.221

Hall, S. (2002) Daubing the drudges of fury: men, violence and the piety of the 'hegemonic masculinity' thesis. Theoretical Criminology 6: 35-61.

Hearn, J. (2004) From hegemonic masculinity to the hegemony of men. Feminist Theory 5: 49-72. http://dx.doi.org/10.1177/1464700104040813

Hutchby, I. and Woo ffi R. (1998) Conversation Analysis: Principles, Practices and Applications. Cambridge: Polity Press.

Jeff erson, G. (1984) Transcription notation. In J. Atkinson and J. Heritage (eds) Structures of Social Interaction ix-Xvi. New York, NY: Cambridge University Press.

Jeff erson, T. (2002) Subordinating hegemonic masculinity. Theoretical Criminology 6: 63-88. http://dx.doi.org/10.1177/136248060200600103

Jewkes, R. and Morrell, R. (2010) Gender and sexuality: emerging perspectives from the heterosexual epidemic in South Africa and implications for HIV risk and prevention. Journal of the International AIDS Society 13: 1-11.

Jørgensen, M. and Phillips, L. (2002) Discourse Analysis: As Theoryand Method. London: Sage Publications.

Kiesling, S.F. (2006) Playing the straight men: displaying and maintaining male heterosexuality in discourse. In D. Cameron and D. Kulick (eds) The Language and Sexuality Reader118-131. London: Routledge.

Kitzinger, C. (2001) Sexualities. In R. K. Unger (ed.) Handbook of the Psychology of Women and Gender272-85. Hoboken, NJ: John Wiley and Sons. 
Kitzinger, C. (2006) Speaking as a heterosexual: (how) does sexuality matter for talk-in-interaction. In D. Cameron and D. Kulick (eds) The Language and Sexuality Reader169-88. London: Routledge.

Kitzinger, C. (2008) Conversation analysis: technical matters for gender research. In K. Harrington, L. Litosseliti, H. Sauntson and J. Sunderland (eds) Gender and Language Research Methodologies119-38. Basingstoke: Palgrave Macmillan.

Light, R. and Kirk, D. (2000) High school rugby, the body and the reproduction of hegemonic masculinity. Sport, Education and Society5: 163-76. http://dx.doi.org/10.1080/713696032

Louw, R. (2001) Mkhumbane and new traditions of (un)African same-sex weddings. In R. Morrell (ed.) Changing Men in Southern Africa 287-96. Pietermaritzburg: University of Natal Press.

Luyt, R. (2003) Rhetorical representations of masculinities in South Africa: moving towards a material-discursive understanding of men. Journal of Community and Applied Social Psychology 13: 46-69. http://dx.doi.org/10.1002/casp.706

Luyt, R. (2005) The Male Attitude Norms Inventory-II: a measure of masculinity ideology in South Africa. Men and Masculinities 8: 208-29. http://dx.doi.org/10.1177/1097184X04264631

Luyt, R. (2011) Representation of gender in South African television advertising: a content analysis. Sex Roles 65: 356-70. http://dx.doi.org/10.1007/s11199-011-0027-0

Luyt, R. (in press) Representation of masculinities and race in South African television advertising: a content analysis. Journal of Gender Studies.

Martino, W. J. (2008) Male teachers as role models: addressing issues of masculinity, pedagogy and the re-masculinization of schooling. Curricu/um Inquiry 38: 189-223. http://dx.doi.org/10.1111/j.1467-873X.2007.00405.X

Marx, K. (1867-1894, 1981) Capital: A Critique of Political Economy(Vols 1-3). Harmondsworth: Penguin Books.

McClendon, T. V. (1995) Tradition and domestic struggle in the courtroom. International Journal of African Historical Studies28: 527-61. http://dx.doi.org/10.2307/221173

Msibi, T. (2009) Not crossing the line: masculinities and homophobic violence in South Africa. Agenda 80: 50-54.

Neuman, W. L. (1997) Social Research Methods: Qualitative and Quantitative Approaches. Boston, MA: Allyn and Bacon.

Pomerantz, A. (1986) Extreme case formulations: a way of legitimizing claims. Human Studies 9: 219-29. http://dx.doi.org/10.1007/BF00148128

Potter, J. (1998) Discursive social psychology: from attitudes to evaluative practices. European Review of Social Psychology9: 233-66. http://dx.doi.org/10.1080/14792779843000090

Potter, J. and Wetherell, M. (2001) Discourse analysis. In J. A. Smith, R. Harré and L. van Langenhove (eds) Rethinking Methods in Psychology80-92. London: Sage Publications.

Potter, J. and Wetherell, M. (2005) Discourse and Social Psychology: Beyond Attitudes and Behaviour. London: Sage Publications.

Paechter, C. (2001) Using poststructuralist ideas in gender theory and research. In B. Francis and C. Skelton (eds) Investigating Gender: Contemporary Perspectives in Education 41-51. Buckingham: Open University Press.

Radley, A. and Billig, M. (1996) Accounts of health and illness: dilemmas and representations. Sociology of Health and IIIness 18: 220-40. http://dx.doi.org/10.1111/1467-9566.ep10934984

Ragnarsson, A., Onya, H. E., Thorson, A., Ekström, A. M. and Aarø, L.E. (2008) Young males' gendered sexuality in the era of HIV and AIDS in Limpopo Province, South Africa. Qualitative Health Research18: 739-46. http://dx.doi.org/10.1177/1049732308318373 
Reeser, T.W. (2010) Masculinities in Theory:An Introduction. Oxford: WileyBlackwell. http://dx.doi.org/10.1002/9781444317312

Rich, A. (1980) Compulsory heterosexuality and lesbian existence. Signs 5: 631-60. http://dx.doi.org/10.1086/493756

Rogers, A. (2005) Chaos to control: men's magazines and the mastering of intimacy. Men \& Masculinities 8: 175-94. http://dx.doi.org/10.1177/1097184X04265319

Sacks, H. (1964-1965, 1992) Lectures on Conversation. Oxford: Basil Blackwell.

Schippers, M. (2007) Recovering the feminine other: masculinity, femininity, and gender hegemony. Theory and Society 36: 85-102. http://dx.doi.org/10.1007/s11186-007-9022-4

Speer, S. A. (2001) Reconsidering the concept of hegemonic masculinity: discursive psychology, conversation analysis and participants' orientations. Feminism \& Psychology 11: 107-135. http://dx.doi.org/10.1177/0959353501011001006

Swart, S. (2001) 'Man, gun, and horse': hard right Afrikaner masculine identity in post-Apartheid South Africa. In R. Morrell (ed.) Changing Men in Southern Africa 75-89. Pietermaritzburg: University of Natal Press.

Swart, S. (2004) 'Men of influence': the ontology of leadership in the 1914 Boer Rebellion. Journal of Historical Sociology 17: 1-30. http://dx.doi.org/10.1111/j.0952-1909.2004.00224.x

Swartz, L. (1998) Culture and Mental Health: A Southern African View. Cape Town: Oxford University Press.

van Zyl, M. (2011) Are same-sex marriages unAfrican? Same-sex relationships and belonging in post-apartheid South Africa. Journal of Social Issues 67: 335-57. http://dx.doi.org/10.1111/j.1540-4560.2011.01701.x

Visser, G. (2003) Gay men, tourism and urban space: reflections on Africa's 'gay capital'. Tourism Geographies5: 168-89. http://dx.doi.org/10.1080/1461668032000068261

Wetherell, M. (2001) Debates in discourse research. In M. Wetherell, S. Taylor and S. J. Yates (eds) Discourse Theoryand Practice: A Reader380-99. London: Sage Publications.

Wetherell, M. and Edley, N. (1999) Negotiating hegemonic masculinity: imaginary positions and psycho-discursive practices. Feminism \& Psychology 9: 335-56. http://dx.doi.org/10.1177/0959353599009003012

Whitehead, S. (1999) Hegemonic masculinity revisited. Gender, Work \& Organization 6: 58-62. http://dx.doi.org/10.1111/1468-0432.00069

Wilkinson, S. (1998) Focus groups in feminist research: power, interaction, and the co-construction of meaning. Women's Studies International Forum 21: 111-25. http://dx.doi.org/10.1016/S0277-5395(97)00080-0

Wilkinson, S. (2001) Theoretical perspectives on women and gender. In R. K. Unger (ed.) Handbook of the Psychology of Women and Gender 17-28. Hoboken, NJ: John Wiley and Sons.

Woo ffi R. (2005) Conversation Analysis and Discourse Analysis: A Comparative and Critical Introduction. London: Sage Publications.

Wood, L. A. and Kroger, R. O. (2000) Doing Discourse Analysis. Thousand Oaks, CA: Sage Publications 